\title{
Optimal venous drainage for the pulmonary allograft: The search goes on
}

\author{
Alexander Sasha Krupnick, MD, and Daniel Kreisel, MD, PhD
}

\footnotetext{
From the Division of Cardiothoracic Surgery, Departments of Surgery, Pathology, and Immunology, Washington University in St Louis, St Louis, Mo.

Disclosures: Authors have nothing to disclose with regard to commercial support.

Received for publication March 6, 2016; accepted for publication March 8, 2016; available ahead of print April $15,2016$.

Address for reprints: Alexander Sasha Krupnick, MD, Division of Cardiothoracic Surgery, Washington University in St Louis, St Louis, MO 63110 (E-mail: krupnicka@wudosis.wustl.edu).

J Thorac Cardiovasc Surg 2016;152:e13-4

0022-5223/ $\$ 0.00$

Published by Elsevier Inc. on behalf of The American Association for Thoracic Surgery http://dx.doi.org/10.1016/j.jtcvs.2016.03.023
}

Since the original description of successful human lung transplantation by the Toronto group in $1983,{ }^{1}$ multiple revisions to the surgical technique have been described. The cumbersome method of telescoping the bronchial anastomosis and wrapping it with omentum has been replaced by a single-layer anastomosis of running or interrupted polyester, poly (p-dioxanone) (PDS, Ethicon, Somerville, NJ) suture at the Washington University in St Louis and most other institutions. ${ }^{2,3}$ However, the venous drainage of the lung graft continues to remain an area of controversy and technical difficulty. Although the classically described method of atrial to atrial anastomosis, with control of the recipient atrium by a proximally placed clamp, is still the preferred method, technical issues prevent this option at times. Trouble can occur as the result of an extremely posterior inferior vein or a common recipient or donor venous trunk, a situation described by Chen-Yoshikawa and colleagues ${ }^{4}$ in this issue of the Journal.

Several techniques have been described to facilitate the difficult venous anastomosis. Arango Tomás and colleagues 5 recently described a case series of complete venous drainage solely through the superior pulmonary vein. Although this technique was feasible in only select patients with a dilated superior vein, it allows avoidance of extensive cardiac manipulation for atrial exposure. Despite technical success and adequate drainage, high mortality was evident in this series, most likely due to the illness of the patients requiring a single venous anastomosis. ${ }^{5}$ Casula and colleagues ${ }^{6}$ describe a technique of augmenting the donor venous cuff with autologous pericardium to facilitate drainage. Although described as a technique to ease the anastomosis of a short donor venous cuff, it also can easily be repurposed to deal with anatomic difficulties in the recipient. Other techniques for difficult venous exposure and avoidance of cardiopulmonary bypass, such as retraction of the beating heart via the Medtronic Urchin (Medtronic Inc, Minneapolis, Minn) heart positioner device, have been described.

In this issue of the Journal, the lung transplant group from Kyoto University describes a successful technique of

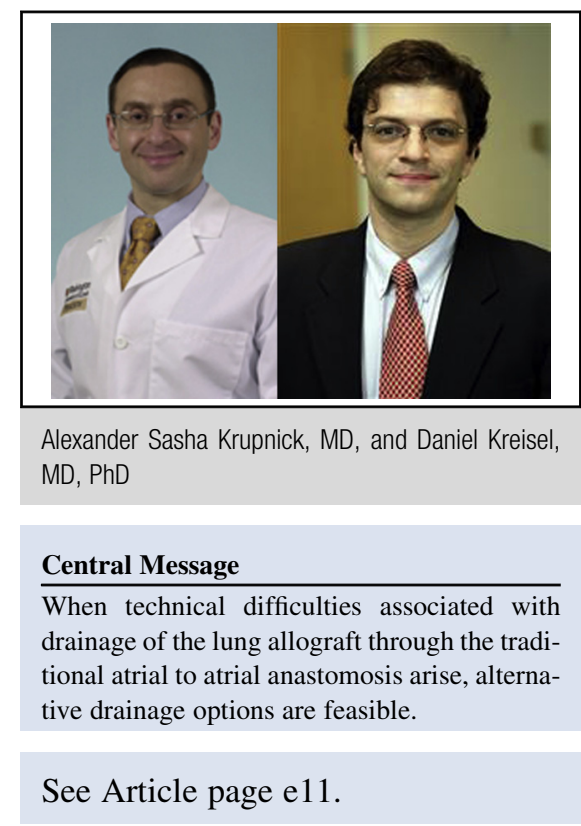

separate venous anastomoses of the inferior pulmonary vein to the common venous trunk and superior pulmonary vein to the left atrial appendage. Their case report adds to the series of similar techniques described in 2 reports by Massad and colleagues ${ }^{8}$ and Khasati and colleagues ${ }^{9}$ for complete left allograft drainage through the left atrial appendage in a donor with a single pulmonary vein. Because pulmonary venous anastomotic problems significantly contribute to patient morbidity and mortality, the knowledge that several variations in the technique can be safely and successfully used provides a level of reassurance to the lung transplant surgeon.

\section{References}

1. Cooper JD, Pearson FG, Patterson GA, Todd TR, Ginsberg RJ, Goldberg M, et al. Technique of successful lung transplantation in humans. J Thorac Cardiovasc Surg. 1987;93:173-81.

2. Kreisel D, Krupnick AS, Puri V, Guthrie TJ, Trulock EP, Meyers BF, et al. Shortand long-term outcomes of 1000 adult lung transplant recipients at a single center. J Thorac Cardiovasc Surg. 2011;141:215-22.

3. Hayanga JW, D'Cunha J. The surgical technique of bilateral sequential lung transplantation. J Thorac Dis. 2014;6:1063-9.

4. Chen-Yoshikawa TF, Goda Y, Dong L, Date H. Separate pulmonary venous anastomoses using a left atrial appendage in a left single lung transplantation. J Thorac Cardiovasc Surg. 2016;152:e11-2.

5. Arango Tomás E, Cerezo Madueño F, Salvatierra Velázquez A. Technique resource for difficult auricular anastomosis in lung transplantation. Transplant Proc. 2015;47:2653-5.

6. Casula RP, Stoica SC, Wallwork J, Dunning J. Pulmonary vein augmentation for single lung transplantation. Ann Thorac Surg. 2001;71:1373-4. 
7. Lau CL, Hoganson DM, Meyers BF, Damiano RJ Jr, Patterson GA. Use of an apical heart suction device for exposure in lung transplantation. Ann Thorac Surg. 2006;81:1524-5.

8. Massad MG, Sirois C, Tripathy S, Jaffe HA, Snow N, Geha AS Pulmonary venous drainage into the left atrial appendage facilitates transplantation of the left lung with difficult exposure. Ann Thorac Surg. 2001;71: 1046-7.
9. Khasati NH, MacHaal A, Thekkudan J, Kumar S, Yonan N. An aberrant donor pulmonary vein during lung transplant: a surgical challenge. Ann Thorac Surg. 2005; 79:330-1.

10. Leibowitz DW, Smith CR, Michler RE, Ginsburg M, Schulman LL, McGregor CC, et al. Incidence of pulmonary vein complications after lung transplantation: a prospective transesophageal echocardiographic study. J Am Coll Cardiol. 1994;24:671-5. 